\title{
Characteristics of reversible and nonreversible COPD and asthma and COPD overlap syndrome patients: an analysis of salbutamol Easyhaler data
}

This article was published in the following Dove Press journal: International Journal of COPD

12 January 2016

Number of times this article has been viewed

\author{
Veronika Müller' \\ Gabriella Gálffy' \\ Márta Orosz' \\ Zsuzsanna Kováts' \\ Balázs Odler' \\ Olof Selroos² \\ Lilla Tamási'
}

'Department of Pulmonology, Semmelweis University, Budapest, Hungary; ${ }^{2}$ Semeco AB, Ängelholm, Sweden
Correspondence: Veronika Müller Department of Pulmonology, Semmelweis University, Diós árok 1/c, II 25 Budapest, Hungary

Tel +36 I 3559733

Fax +36 I 2142498

Email muller.veronika@med.

semmelweis-univ.hu

\begin{abstract}
The choice of inhaler device for bronchodilator reversibility is crucial since suboptimal inhalation technique may influence the result. On the other hand, bronchodilator response also varies from time to time and may depend on patient characteristics. In this study, patients with airway obstruction (forced expiratory volume in 1 second $\left[\mathrm{FEV}_{1}\right] /$ forced vital capacity [FVC] ratio $<70 \%$ in chronic obstructive pulmonary disease [COPD]; $<80 \%$ in asthma) were included ( $n=121$, age: $57.8 \pm 17.3$ years). Bronchodilator reversibility (American Thoracic Society/European Respiratory Society criteria) was tested in patients with COPD $(n=63)$ and asthma and COPD overlap syndrome (ACOS; n=12). Forty-six asthmatics served as controls. Reversibility was tested with $400 \mu \mathrm{g}$ salbutamol dry powder inhaler (Buventol Easyhaler, Orion Pharma Ltd, Espoo, Finland). Demographic data and patients' perceptions of Easyhaler compared with $\beta_{2}$-agonist pressurized metered dose inhalers (pMDIs) were analyzed. American Thoracic Society/European Respiratory Society guideline defined reversibility was found in 21 out of 63 COPD patients and in two out of 12 ACOS patients. Airway obstruction was more severe in COPD patients as compared with controls (mean $\mathrm{FEV}_{1}$ and $\mathrm{FEV}_{1} \%$ predicted both $P<0.0001$ ). Average response to salbutamol was significantly lower in COPD patients compared with asthma controls $(P<0.0001)$. Reversibility was equally often found in smokers as in never-smokers (33\% vs 34\%). Nonreversible COPD patients had higher mean weight, body mass index, and $\mathrm{FEV}_{1} / \mathrm{FVC}$ compared with reversible COPD patients. Most patients preferred Easyhaler and defined its use as simpler and more effective than use of a pMDI. Never-smokers and patients with asthma experienced Easyhaler somewhat easier to use than smokers and patients with COPD. In conclusion, a substantial part of patients with COPD or ACOS showed reversibility to salbutamol dry powder inhaler. Nonreversible patients with COPD were characterized by higher weight and body mass index, and a higher $\mathrm{FEV}_{1} / \mathrm{FVC}$ ratio. Most patients preferred Easyhaler compared with a pMDI.
\end{abstract}

Keywords: ACOS, asthma, bronchodilator reversibility, COPD, Easyhaler, salbutamol

\section{Introduction}

Chronic obstructive pulmonary disease (COPD) is a common disease. It has been estimated that 23 million people in Europe are living with COPD stage II-IV and that 17 million have stage I disease. ${ }^{1}$ The annual cost of COPD in Europe, including health care costs, has been estimated to be $€ 141$ billion. Furthermore, the prevalence of the disease is predicted to increase until at least $2030{ }^{1}$

For diagnosis, patients should have a ratio between forced expiratory volume in 1 second $\left(\mathrm{FEV}_{1}\right)$ and forced vital capacity $(\mathrm{FVC})$ of less than $70 \%$ postbronchodilator ( $<65 \%$ in patients above the age of 65 years). ${ }^{2,3}$ In recent years, it has become evident that several phenotypes of COPD exist. ${ }^{4}$ An additional phenotype is the asthma and COPD overlap syndrome (ACOS). ${ }^{5}$ 
There are differences but also similarities between COPD and asthma. ${ }^{6,7}$ In contrast to asthma, COPD is characterized by airflow limitation that is not fully reversible. ${ }^{2}$ If this would always be true, the physiological difference between COPD and asthma could consequently be defined in the degree of reversibility of the actual airway obstruction.

In both asthma and COPD, the key diagnostic tool is measurement of lung function. If airway obstruction is present, reversibility to a RABA should be tested. However, asthma patients may be nonreversible when the baseline $\mathrm{FEV}_{1}$ is close to the predicted normal value, and patients with COPD may show significant reversibility. The "Understanding Potential Long-term Impacts on Function with Tiotropium" study showed that at baseline $54 \%$ of the more than 5,000 patients with moderate-to-severe COPD had a reversibility when tested with $80 \mu \mathrm{g}$ ipratropium followed by $400 \mu \mathrm{g}$ salbutamol of $\geq 12 \%$ and $\geq 200 \mathrm{~mL}{ }^{8}$ Two-thirds of the patients showed an improvement of $\geq 15 \%$ of $\mathrm{FEV}_{1}$ predicted normal. ${ }^{8}$

Many studies show that the individual COPD patient's response varies from time to time and depends on patient characteristics. ${ }^{9}$ As a consequence, treatment guidelines no longer advocate reversibility testing as part of routine assessment of patients with COPD. ${ }^{10} \mathrm{ACOS}$ is a challenging phenotype of obstructive airway disease with a physician diagnosis of both asthma and COPD. These patients may have a history or evidence of atopy, smoking $>10$ pack-years, bronchial hyperresponsiveness, and postbronchodilator $\mathrm{FEV}_{1}<80 \%$ predicted and $\mathrm{FEV}_{1} / \mathrm{FVC}<70 \%$. Methacholine inhalation provocation test may demonstrate significant bronchoconstriction. Bronchodilator reversibility is a key diagnostic feature including $\geq 15 \%$ increase in $\mathrm{FEV}_{1}$ or $\geq 12 \%$ and $\geq 200 \mathrm{~mL}$ increase in postbronchodilator $\mathrm{FEV}_{1}$ in separate measurements. ${ }^{2,11}$

Formulations of salbutamol include pressurized metered dose inhalers (pMDIs), dry powder inhalers (DPIs), and solutions for nebulization. It is known that choice of the correct inhaler device is crucial since suboptimal inhalation techniques can result in reduced drug delivery and efficacy and it should be adjusted to different patients, ${ }^{12}$ hence the device used for reversibility testing may influence the result. A meta-analysis of randomized controlled trials comparing the same drug delivered by different devices concluded that efficacy outcomes do not differ significantly, and that pMDIs and DPIs are equally efficacious in clinical settings, ${ }^{13,14}$ although studies have shown that there are fewer inhalation errors with some DPIs. ${ }^{15-17}$ Therefore, from that point of view it may be an advantage to perform reversibility testing by using a DPI. Clinical studies have shown the DPI Easyhaler (Orion Pharma AB, Espoo, Finland) to be easy to use and preferred by patients compared with a pMDI. ${ }^{18,19}$

\section{Aim of the study}

The aim of this data analysis was to evaluate bronchodilator response to salbutamol Easyhaler in patients with clinically diagnosed COPD and ACOS with confirmed airway obstruction, and in patients with asthma. Different smoking habits and demographic characteristics of enrolled patients were analyzed. All patients received standard care for their obstructive lung disease. Additionally, patients' rapid-acting $\beta_{2}$-agonist use and perception of the easiness of salbutamol delivery formulations were also assessed.

\section{Ethical approval}

The study was approved by the Institutional Ethics Committee of the Department of Pulmonology at Semmelweis University. No informed consent was obtained from the participants as it was a noninterventional retrospective data analysis of real-life data collected on regular visits of the patients. No intervention was done for the sake of the study.

\section{Materials and methods Study design and patients}

This real-life study had a cross-sectional design and involved 151 Caucasian outpatients or inpatients from the Department of Pulmonology, Semmelweis University, Budapest, Hungary. Patients were consecutively recruited during their regular visits or before discharge from the department. COPD and ACOS patients were included in the main analysis and asthma patients served as controls. All patients underwent spirometry, and if airway obstruction was confirmed $\left(\mathrm{FEV}_{1} / \mathrm{FVC}<80 \%\right.$ in asthma; $<70 \%$ in COPD), bronchodilator reversibility was conducted. A total of 121 patients showed airway obstruction at the time of the test. All patients were asked not to take regular bronchodilator medications 12 hours before the testing.

Male and female patients aged above 18 years were eligible for inclusion in the study if: 1) they had a diagnosis of COPD or asthma confirmed by chest physician; 2) diagnosis confirmed at least 6 months before reversibility testing; 3) they had not changed their maintenance medication within the last 4 weeks prior to reversibility testing; 4) they had no acute exacerbation within the last 4 weeks prior to reversibility testing, but could have been hospitalized for rehabilitation purposes. Patients were enrolled regardless of their smoking history or habit. Data on sex, age, diagnosis, body mass index (BMI), and smoking history were collected. 


\section{Spirometry measurements}

Spirometry was performed using an electronic spirometer (PDD-301/s, Piston, Budapest, Hungary) according to the American Thoracic Society (ATS) guidelines. ${ }^{20}$ Data on $\mathrm{FEV}_{1}$, FVC, total lung capacity, residual volume, and airway resistance were collected. Lung function was also expressed as $\mathrm{FEV}_{\mathrm{l}} /$ $\mathrm{FVC}$ and as $\mathrm{FEV}_{1} \%$ predicted normal. In cases of confirmed obstruction, $400 \mu \mathrm{g}$ salbutamol delivered via the DPI Easyhaler (Buventol Easyhaler, Orion Pharma) was administered and measurements were repeated 15-20 minutes after inhalation.

\section{Device preference for inhaled rapid- acting $\beta_{2}$-agonists}

Patients were asked about their former use of rapid-acting $\beta_{2}$-agonists. Patients answered questions comparing Easyhaler DPI or classic pMDI with respect to the easiness of use, perceived bronchodilator effect, and effects on sputum expectoration.

\section{Statistical analysis}

Data were analyzed with the IBM SPSS 20.0 statistical program package. Differences between groups were tested by one-way analysis of variance. Categorical variables were compared by chi-square test. Correlations were tested with Pearson's two-tailed correlation. The level of significance was set at 0.05 .

Logistic regression model was used to discover deeper relations with reversibility. The model included the following independent variables: sex, weight $(\mathrm{kg}), \mathrm{BMI}\left(\mathrm{kg} / \mathrm{m}^{2}\right)$, smoking, and equipment (inhaler); and as the dependent variable: reversibility.

\section{Results}

\section{Clinical data of the patients}

A total of 151 patients with airway obstruction were tested. The analysis included 121 patients (72 women and 49 men) who had airway obstruction. There were 63 patients with COPD and 12 with ACOS. The control group consisted of 46 patients with asthma. The sex distribution in relation to diagnoses is shown in Figure 1. The majority of the patients were outpatients. The patients with COPD were older (mean age 63 years) compared with the patients with asthma (mean age 50 years).

There were 37 (30\%) current smokers, 46 (38\%) exsmokers, and 38 never-smokers (32\%). Thirty-three of the 37 smokers (89\%) had COPD. The distribution of diagnoses in relation to smoking habits is shown in Figure 2.

The baseline characteristics of the patients are summarized in Table 1. The COPD patients had significantly lower

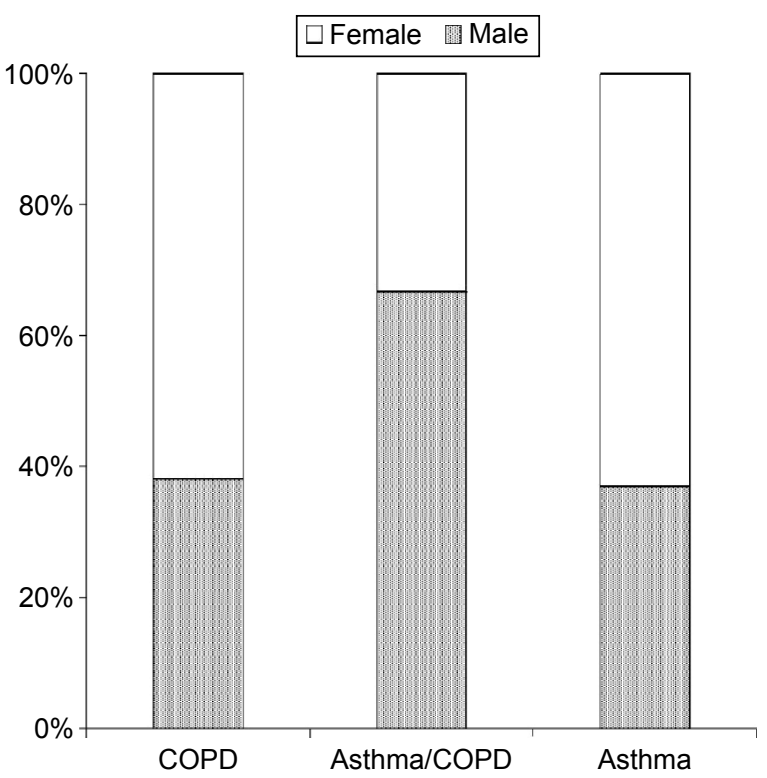

Figure I Sex distribution among patients with COPD, ACOS, and asthma (\%). Abbreviations: ACOS, asthma and COPD overlap syndrome; COPD, chronic obstructive pulmonary disease.

baseline $\mathrm{FEV}_{1}, \mathrm{FEV}_{1} \%$ predicted, and $\mathrm{FEV}_{1} / \mathrm{FVC}$ ratio than the patients with asthma. The COPD patients had higher mean values for airway resistance and residual volume than the patients with asthma. Total lung capacities did not differ between the groups. BMI mean values were similar in all groups.

The group of patients with ACOS was of a similar mean age as the patients with COPD, but had lung function values

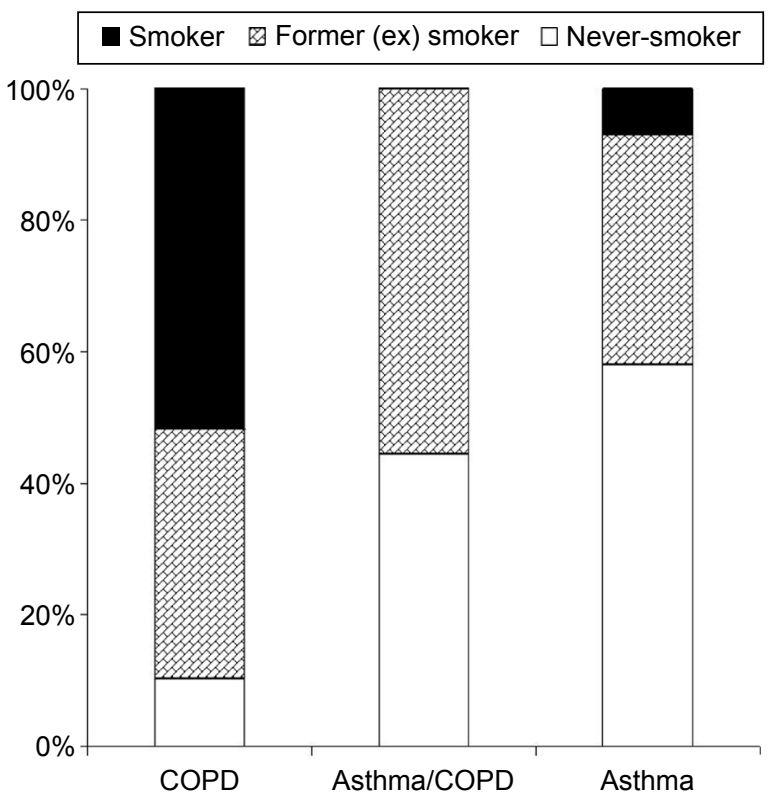

Figure 2 Smoking habits among patients with COPD, ACOS, and asthma (\%). Abbreviations: ACOS, asthma and COPD overlap syndrome; COPD, chronic obstructive pulmonary disease. 
Table I Baseline characteristics and prebronchodilator lung function values in patients with COPD, ACOS, and asthma controls

\begin{tabular}{|c|c|c|c|c|c|}
\hline Variable & All $(n=|2|)$ & Asthma $(n=46)$ & COPD $(n=63)$ & Asthma/COPD $(n=12)$ & Overall $P$-value \\
\hline Age & $57.8 \pm 17.3$ & $50.2 \pm 21.0$ & $62.8 \pm 11.8^{\#}$ & $60.8 \pm 16.5$ & $<0.0001$ \\
\hline Male/female (n) & $49 / 72$ & $17 / 29$ & $24 / 39$ & $8 / 4$ & 0.152 \\
\hline Smoker: current/ex/non (n) & $33 / 42 / 35$ & $3 / 15 / 25$ & $30 / 22 / 6$ & $0 / 5 / 4$ & $<0.0001$ \\
\hline Outpatient/inpatient (n) & $87 / 24$ & $37 / 6$ & $43 / 17$ & $7 / 1$ & 0.179 \\
\hline Weight $(\mathrm{kg})$ & $74.25 \pm 16.85$ & $75.07 \pm 17.23$ & $72.70 \pm 16.94$ & $79.25 \pm 14.87$ & 0.431 \\
\hline Height $(\mathrm{cm})$ & $166.78 \pm 8.79$ & $167.59 \pm 9.94$ & $165.75 \pm 8.06$ & $169.08 \pm 7.66$ & 0.356 \\
\hline BMI $\left(\mathrm{kg} / \mathrm{m}^{2}\right)$ & $26.64 \pm 5.52$ & $26.7 I \pm 5.60$ & $26.39 \pm 5.62$ & $27.73 \pm 4.89$ & 0.741 \\
\hline Pre-FVC (L) & $2.67 \pm 1.07$ & $3.09 \pm 1.27^{*}$ & $2.31 \pm 0.84$ & $2.93 \pm 0.72$ & $<0.0001$ \\
\hline Pre-FVC\% predicted & $79.84 \pm 19.56$ & $88.33 \pm 19.48 *$ & $72.94 \pm 17.72$ & $83.58 \pm 16.21$ & $<0.0001$ \\
\hline Pre-FEV $(\mathrm{L})$ & $1.63 \pm 0.78$ & $1.98 \pm 0.86 *$ & $1.32 \pm 0.61$ & $1.93 \pm 0.56$ & $<0.0001$ \\
\hline Pre-FEV $\%$ predicted & $58.97 \pm|8.6|$ & $67.93 \pm|6.7|^{*}$ & $50.60 \pm 16.74$ & $68.50 \pm 14.88$ & $<0.000 \mathrm{I}$ \\
\hline Pre-FEV,/FVC & $60.29 \pm 10.56$ & $63.97 \pm 7.58^{*}$ & $56.56 \pm 11.60$ & $65.74 \pm 7.39$ & $<0.000 \mathrm{I}$ \\
\hline Pre-TLC (L) & $6.13 \pm 1.24$ & $6.17 \pm 1.32$ & $6.11 \pm 1.26$ & $6.08 \pm 0.76$ & 0.965 \\
\hline Pre-TLC\% predicted & $109.64 \pm 20.46$ & $109.95 \pm 19.52$ & $111.03 \pm 21.76$ & $101.25 \pm 15.50$ & 0.316 \\
\hline Pre-RV (L) & $3.16 \pm 1.04$ & $2.79 \pm 0.73$ & $3.49 \pm 1.16^{\#}$ & $2.80 \pm 0.74$ & 0.001 \\
\hline Pre-RV\% predicted & $157.30 \pm 52.75$ & $150.35 \pm 48.62$ & $167.56 \pm 55.99^{\#}$ & $128.33 \pm 34.59$ & 0.033 \\
\hline Pre-Raw (kPa/s) & $0.52 \pm 0.36$ & $0.42 \pm 0.17$ & $0.62 \pm 0.46^{\#}$ & $0.34 \pm 0.11$ & 0.003 \\
\hline
\end{tabular}

Notes: Data expressed as mean \pm standard deviation, if not stated otherwise. *Asthma statistically significantly greater than COPD (asthma vs COPD $P<0.05)$. ${ }^{*}$ COPD statistically significantly greater than asthma (COPD vs asthma $P<0.05)$.

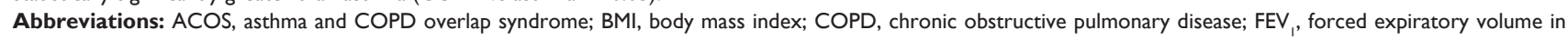
I second; FVC, forced vital capacity; Pre, prebronchodilator; Post, postbronchodilator; Raw, airway resistance; RV, residual volume; TLC, total lung capacity.

$\left(\mathrm{FEV}_{1}, \mathrm{FEV}_{1} / \mathrm{FVC}\right.$, and $\mathrm{FEV}_{1} \%$ predicted normal $)$ very close to the control group of patients with asthma.

\section{Postbronchodilator lung function}

The mean lung function values of the patients after inhalation of $400 \mu \mathrm{g}$ salbutamol via Easyhaler are shown in Table 2. The mean improvement in $\mathrm{FEV}_{1}$ was $+0.12 \mathrm{~L}$ in the COPD group, which was significantly lower than the reversibility in the control asthma group (+0.26 L). In the ACOS group, the mean increase in $\mathrm{FEV}_{1}$ was exactly the same as in the asthma group, +0.26 L. Reversibility defined according to ATS/ European Respiratory Society (ATS/ERS) criteria was seen in
41 patients (34\%). A higher proportion of the asthma and COPD patients demonstrated reversibility compared with patients in the ACOS group (Figure 3). A total of 21 patients with COPD (33\%) improved $\geq 12 \%$ and $\geq 200 \mathrm{~mL}^{\text {in }} \mathrm{FEV}_{1}$, compared with 18 patients with asthma (39\%). Only two out of 12 patients in the ACOS group (17\%) showed reversibility.

\section{Influence of clinical factors on reversibility}

Smoking status did not influence reversibility. Approximately one-third of not only the never-smokers but also the active smokers demonstrated reversibility (Figure 4).

Table 2 Lung function values after inhalation of $400 \mu \mathrm{g}$ salbutamol via Easyhaler dry powder inhaler

\begin{tabular}{|c|c|c|c|c|}
\hline Variable & COPD $(n=63)$ & $\operatorname{Acos}(n=12)$ & Controls (asthma) $(n=46)$ & Overall $P$-value \\
\hline Post-FVC (L) & $2.50 \pm 0.85$ & $3.05 \pm 0.75$ & $3.30 \pm 1.23 *$ & $<0.000 \mathrm{I}$ \\
\hline Post-FVC\% predicted & $79.08 \pm 18.34$ & $87.58 \pm 18.94$ & $94.72 \pm 18.39 *$ & $<0.0001$ \\
\hline Post-FEV $(\mathrm{L})$ & $1.44 \pm 0.65$ & $2.05 \pm 0.57$ & $2.24 \pm 0.96 *$ & $<0.000$ I \\
\hline Post-FEV $\%$ predicted & $55.27 \pm 17.46$ & $73.17 \pm 15.80$ & $77.09 \pm 19.12^{*}$ & $<0.0001$ \\
\hline Post-FEV/FVC & $56.88 \pm 11.95$ & $67.37 \pm 7.48$ & $67.24 \pm 8.79 *$ & $<0.0001$ \\
\hline Post-TLC (L) & $6.18 \pm 1.38$ & $6.00 \pm 0.83$ & $6.11 \pm 1.30$ & 0.904 \\
\hline Post-TLC\% predicted & $112.35 \pm 21.10^{\#}$ & $91.58 \pm 30.10$ & $109.19 \pm|8.9|$ & 0.011 \\
\hline Post-RV (L) & $3.4 I \pm I .2 I^{\#}$ & $2.56 \pm 0.75$ & $2.53 \pm 0.77$ & $<0.0001$ \\
\hline Post-RV\% predicted & $161.85 \pm 51.03^{\#}$ & $116.92 \pm 34.07$ & $135.74 \pm 45.59$ & 0.002 \\
\hline Post-Raw (kPa/s) & $0.45 \pm 0.28^{\#}$ & $0.24 \pm 0.07$ & $0.31 \pm 0.14$ & 0.000 \\
\hline
\end{tabular}

Notes: Data expressed as mean \pm standard deviation, if not stated otherwise. *COPD statistically significantly inferior compared with asthma (asthma vs COPD $P<0.05$ ). \#COPD statistically significantly greater than asthma (COPD vs asthma $P<0.05$ ).

Abbreviations: ACOS, asthma and COPD overlap syndrome; COPD, chronic obstructive pulmonary disease; FEV ${ }_{1}$, forced expiratory volume in I second; FVC, forced vital capacity; Post, postbronchodilator; Raw, airway resistance; RV, residual volume; TLC, total lung capacity. 


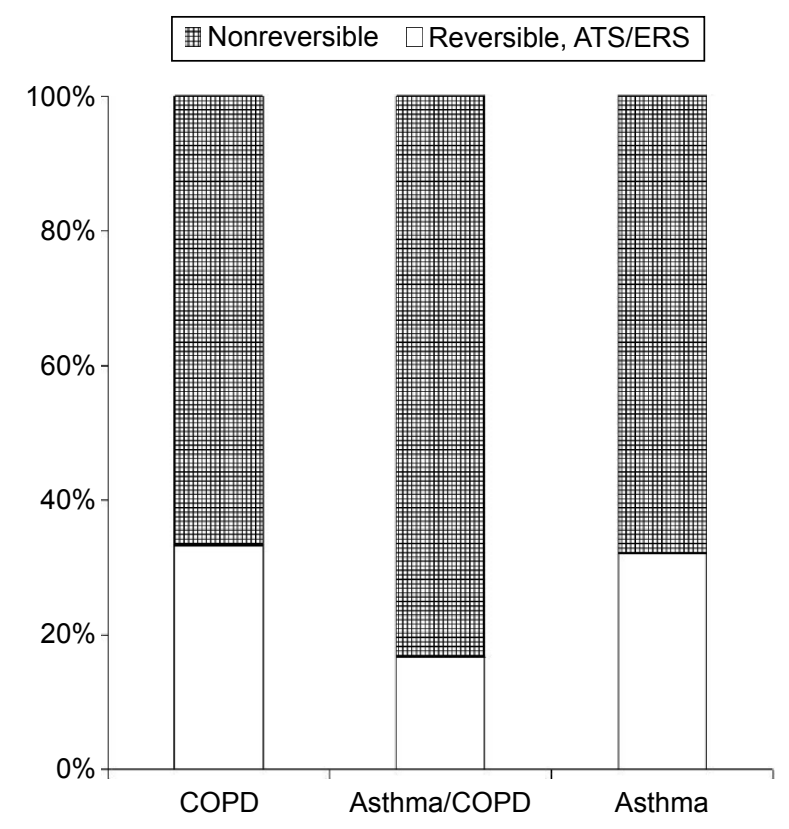

Figure 3 Reversibility in patients with COPD, ACOS, and asthma (\%). Abbreviations: ACOS, asthma and COPD overlap syndrome; ATS/ERS, American Thoracic Society/European Respiratory Society; COPD, chronic obstructive pulmonary disease.

The logistic regression model could predict in $74 \%$ of the cases whether a patient was reversible or not. Only weight was a single significant predictor of reversibility. No other statistically significant or clinically important relationships were found.

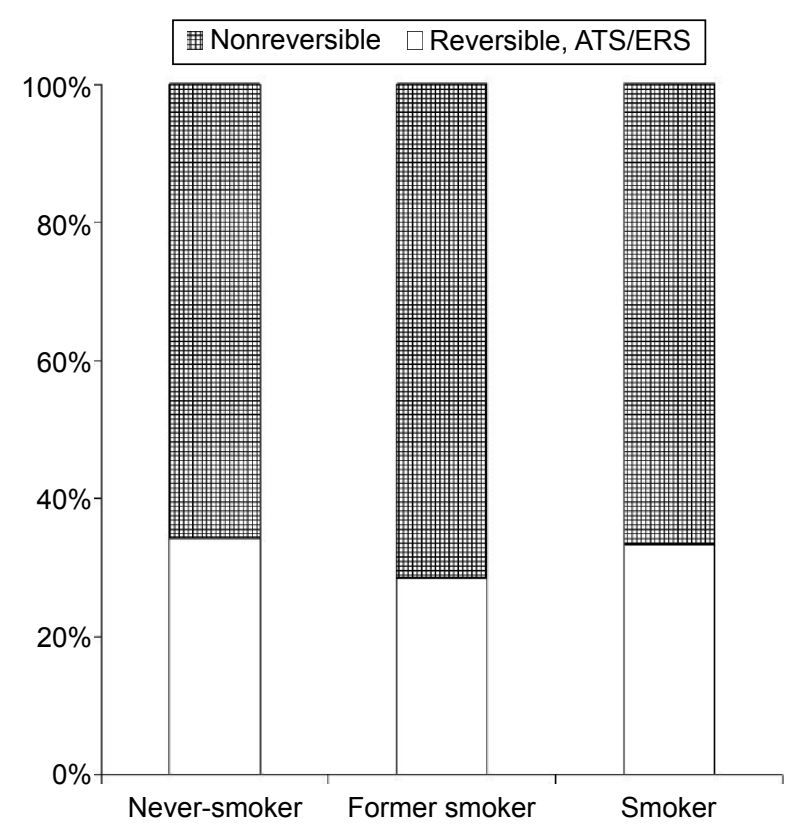

Figure 4 Reversibility in relation to smoking habits in patients with COPD, ACOS, and asthma (\%).

Abbreviations: ACOS, asthma and COPD overlap syndrome; ATS/ERS, American Thoracic Society/European Respiratory Society.
A comparison between reversible and nonreversible COPD patients is shown in Table 3. The nonreversible COPD patients had significantly higher mean weight, BMI, and higher $\mathrm{FEV}_{1} / \mathrm{FVC}$ ratio compared with the reversible patients with COPD. The low sample size in the ACOS group did not provide enough data for a statistical comparison between reversible and nonreversible patients, as only two ACOS patients exhibited airway reversibility with salbutamol.

\section{Patients' evaluation of Easyhaler dry powder inhaler}

The majority of the patients were using an inhaled rapidacting bronchodilator (RABA) at the time of the study (Figure 5). Daily bronchodilator use was more common in patients with COPD than in patients with asthma.

The patients found the DPI Easyhaler easy to use and easier than a pMDI (Figure 6). The patients subjectively scored the Easyhaler device to have a greater bronchodilating capacity than a pMDI, to be more effective than a pMDI in inducing expectoration, and in helping in morning activities.

Inhalator perceived differences were not influenced by reversibility.

\section{Discussion}

Testing of airway reversibility is an important diagnostic tool when investigating patients with obstructive airway diseases, particularly in patients with asthma. Traditionally, asthma has been considered a reversible airway disease in contrast to COPD. However, in recent years, it has been recognized that many patients with a clinical diagnosis of COPD, and without signs of asthma, may exhibit a considerable reversibility when tested with rapid-acting $\beta_{2}$-agonists or anticholinergics. ${ }^{8}$ However, to know about reversibility when planning the treatment of patients with COPD is clinically important.

It is important to emphasize that COPD patients with reversible airflow obstruction might also include cases of ACOS. ${ }^{11}$ This newly introduced entity into Global Initiative for Asthma and Global Initiative for Chronic Obstructive Lung Disease (GOLD) guidelines is mainly based on clinical appearance and physician's judgment. However, repeatedly measured reversibility might increase the number of ACOS patients in a COPD cohort and consequently have impact on therapy. ${ }^{2}$ This is important because having ACOS predicts a low health-related quality of life ${ }^{21}$ and these patients have a high rate of hospitalizations 
Table 3 Characteristics of reversible and nonreversible patients with COPD

\begin{tabular}{llll}
\hline Variable & COPD reversible & COPD nonreversible & P-value \\
\hline Age (years) & 61.6 & 62.4 & 0.790 \\
Male (N) & 10 & 20 & 0.783 \\
Female (N) & 13 & 30 & 0.783 \\
Current and ex-smokers (N) & 17 & 44 & 0.969 \\
Nonsmokers (N) & 2 & 5 & 0.969 \\
Weight $(\mathrm{kg})$ & 64.0 & 77.1 & 0.003 \\
Height $(\mathrm{cm})$ & 165.4 & 166.7 & 0.564 \\
BMI $\left(\mathrm{kg} / \mathrm{m}^{2}\right)$ & 23.3 & 27.7 & 0.001 \\
FEV $(\mathrm{L})$ & 1.38 & 1.62 & 0.188 \\
FEV $\%$ predicted & 52.1 & 60.4 & 0.068 \\
FEV, $/$ FVC & 53.7 & 62.5 & 0.010 \\
FVC $(\mathrm{L})$ & 2.58 & 2.53 & 0.798 \\
FVC\% predicted & 80.7 & 77.9 & 0.537 \\
\hline
\end{tabular}

Abbreviations: BMI, body mass index; COPD, chronic obstructive pulmonary disease; FEV , forced expiratory volume in I second; FVC, forced vital capacity.

compared with patients with asthma or COPD alone. ${ }^{22}$ In a recent study, ACOS and COPD patients were found to have a similar degree of airflow limitation..$^{23}$ In our study, baseline lung function of ACOS patients was similar to asthmatics and better than that of COPD patients. ACOS and asthmatic patients even showed similar degree of hyperinflation, which was milder than the hyperinflation detected in COPD patients. However, the explanation of these diverging observations cannot be stated as the maintenance therapy of the three patient groups remains unknown. Our study showed that despite maintenance treatment

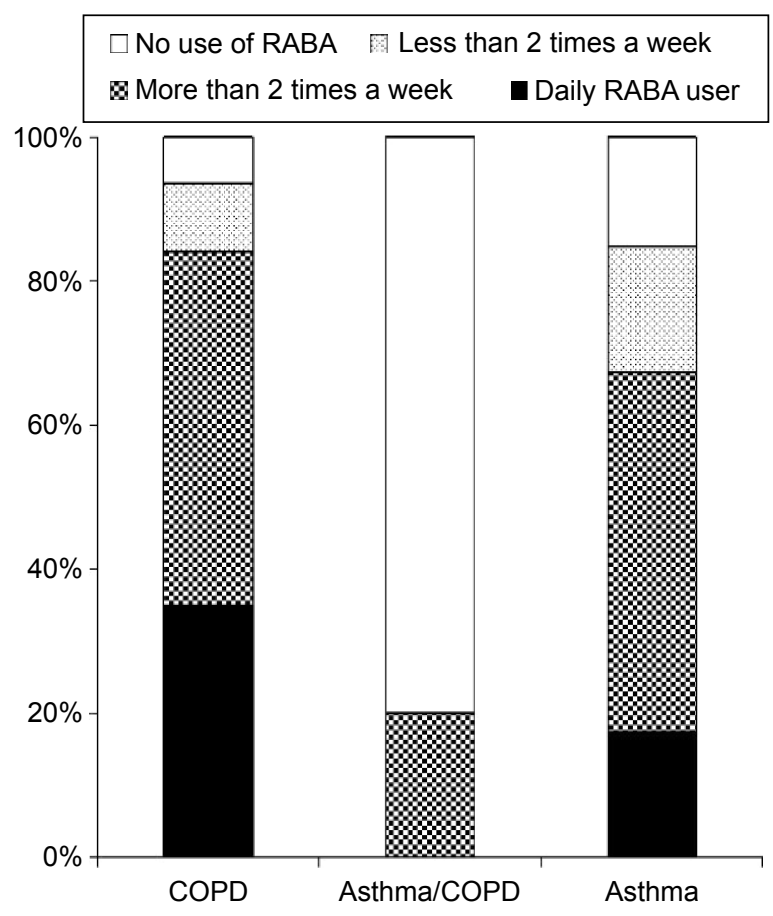

Figure 5 Patients' use of a rapid-acting bronchodilator (RABA) at the time of the study in relation to diagnoses (\%).

Abbreviation: COPD, chronic obstructive pulmonary disease. considered to be adequate for good management of the patients, $121(80 \%)$ of the originally included 151 patients demonstrated airway obstruction. Of these 121 patients, 41 (34\%) demonstrated reversibility according to ATS/ ERS guidelines when tested with $400 \mu \mathrm{g}$ salbutamol via Easyhaler; 21 patients with COPD (33\%), two with ACOS (17\%), and 18 with asthma (39\%). These figures appear to be low and indicate that the patients may have had a long-lasting airway disease with already permanent fixed airway obstruction. However, we do not know whether a different and higher percentage of reversibility would have

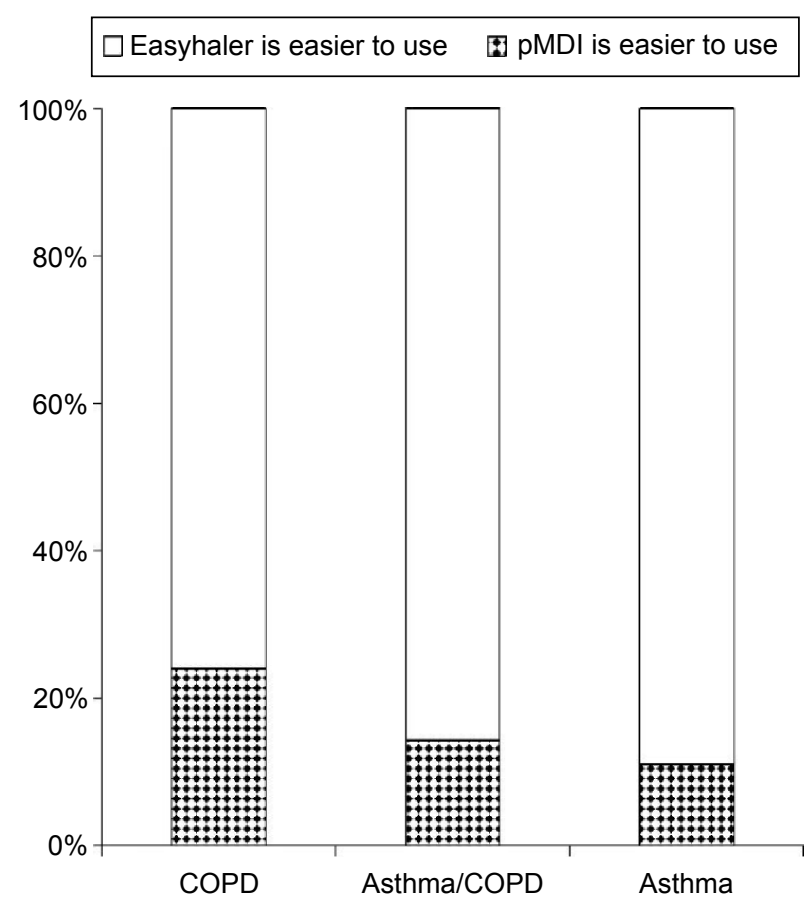

Figure 6 The patients' experience of ease of use of Easyhaler and pMDI. Abbreviations: COPD, chronic obstructive pulmonary disease; pMDI, pressurized metered dose inhaler. 
been demonstrable if the patients had been tested also with salbutamol via a nebulizer or pMDI, due to the known different efficacy of different inhaler devices containing same active compound. ${ }^{24}$ It should also be acknowledged that the percentage of reversible patients only represents the percentage at that time point as reversibility is known to vary significantly from time to time both in asthma and COPD. ${ }^{2,7-9}$ In another recent study in patients with stable COPD but not receiving anti-inflammatory treatment, 31 out of 48 patients (65\%) were found to have airway reversibility with salbutamol. ${ }^{25}$

Several controlled clinical studies have previously compared the bronchodilating efficacy of equal single or cumulative doses of salbutamol delivered via a standard pMDI and the DPI Easyhaler. ${ }^{26-29}$ To the best of our knowledge, this is the first real-life study analyzing one-time reversibility with the salbutamol Easyhaler in patients with COPD and ACOS on regular maintenance therapy for their diseases. The reversibility testing was performed when the patients visited the clinic for regular follow-up visits or just before they were discharged from the hospital. At the time of testing they did not have any new respiratory symptoms. The notable number of patients with reversibility in both diseases can be considered high in a population on regular bronchodilator and/or anti-inflammatory treatment.

It is obvious that an increase in $\mathrm{FEV}_{1}$ in a reversibility test of $<8 \%$ or $<150 \mathrm{~mL}$ are likely to be within measurement variability. ${ }^{30,31}$ To understand reversibility in patients, it is important to know the reversibility in healthy subjects. In a worldwide survey (14 centers), the Burden of Obstructive Lung Disease study reported the response to inhaled salbutamol. ${ }^{32}$ The results indicated that an increase in $\mathrm{FEV}_{1}$ of more than $300 \mathrm{~mL}$ is very unlikely to arise by chance. This equates to a $12 \%$ increase from baseline in people with normal lung function. ${ }^{33}$ Similar absolute changes in FEV were also seen in the healthy comparator data reported by the Evaluation of COPD Longitudinally to Identify Predictive Surrogate Endpoints investigators. ${ }^{34}$

The definition of bronchodilator reversibility has three components. The first is the assessment of the short-term $(<20$ minutes after the test) change in lung function, usually $\mathrm{FEV}_{1}$, after inhalation of a RABA. ${ }^{35}$ It could be a $\beta_{2}$-agonist, an anticholinergic agent, or both. ${ }^{35}$ Second, the change in $\mathrm{FEV}_{1}$ needs to be greater than the change that would be expected by chance and this is expressed as a change greater than $12 \%$ of the baseline value. However, if the baseline value is high, a large absolute change in $\mathrm{FEV}_{1}$ is needed for a positive response, but small changes close to the between-test variability in the measurement can be enough to suggest reversibility when the pretest $\mathrm{FEV}_{1}$ is low. To overcome this requirement, a third pragmatic component was added after the Intermittent Positive Pressure Breathing study, namely a requirement of at least a $200 \mathrm{~mL}$ absolute change. ${ }^{36}$ These values are now included in the ATS/ERS statement on airway reversibility and in the Global Initiative for Asthma and GOLD documents. ${ }^{2,33}$

To define actual airway obstruction in our series of patients, we used a fixed $\mathrm{FEV}_{1} / \mathrm{FVC}$ ratio of $<70 \%$ in patients with COPD and $<80 \%$ in patients with asthma. There is some controversy regarding the cutoff values for $\mathrm{FEV}_{1} /$ FVC in patients with COPD. Early GOLD documents used the $<70 \%$ cutoff, but in 2004, the ERS and ATS issued a statement advocating the use of the lower limit of normal instead of a fixed criterion. ${ }^{37}$ The lower limit of normal is age corrected and defined by the lower fifth percentile of the reference population. It can be calculated by subtracting 1.64 times the standard deviation from the mean, that is, the expected value. One argument for discarding the fixed $\mathrm{FEV}_{1} / \mathrm{FVC}$ ratio of $<0.70$ is that it can lead to a COPD diagnosis in nonsmoking elderly not having the disease. ${ }^{38}$ Nevertheless, we used the fixed ratio as our patients had an established diagnosis of COPD (or asthma) and the question of overdiagnosing elderly was not relevant.

Easyhaler is a DPI with a consistent fine particle dose across a wide range of inspiratory flow rates and high lung deposition, and could therefore be a simple and reliable alternative for airway reversibility testing. ${ }^{39-41}$ It has been found easy to use and considered to come close to an ideal inhalation device by some investigators..$^{29,42}$

Patients in our study expressed a preference for the use of Easyhaler compared with their earlier inhalation devices. The high acceptance of Easyhaler is in line with the results of previous studies, where Easyhaler has been compared with other devices. ${ }^{43}$ Importantly, selection of a proper inhaler in agreement with patients' preferences is a key issue for achieving best possible control of patients with obstructive lung diseases. ${ }^{44} 46$

Our study has obvious limitations. We do not know the reversibility when, for example, a pMDI with or without a spacer would have been used in the same patients. The same is true for using an anticholinergic drug for reversibility testing. We do neither know the reproducibility of the testing as only one test with salbutamol DPI was performed and the majority of the patients were used to pMDIs. If the percentage of patients being reversible at a specific time point may be constant, it only determines the percentage of 
the population that is reversible at that time, not the response of the individual patient.

Thirty percent of the patients in the study were smokers, the majority of them having COPD. An unexpected finding at the first glance was that reversibility was often seen equally in smokers as in never-smokers. The most logical explanation might be that the nonsmokers had lung function values close to their predicted normal values and therefore, reversibility was not possible to demonstrate. It is important to note that smokers are more often considered to have COPD than asthma, however, our former study confirmed that with more effective drug delivery, better asthma control can also be achieved in smokers. ${ }^{47}$

\section{Conclusion}

Our results indicate that despite ongoing maintenance therapy, a substantial part of patients with COPD or asthma showed reversibility to salbutamol DPI. This might represent undertreatment and the need to reassess maintenance medication. Possible cases of ACOS might also be identified. Nonreversible patients with COPD were characterized by higher weight and BMI and a higher $\mathrm{FEV}_{1} / \mathrm{FVC}$ ratio. Patients' preferences of the device might increase compliance with treatment and adherence, so possibility to try different formulations of the given drugs should be offered.

\section{Acknowledgments}

The authors would like to thank Istvan Mezes, VIT Ltd and Balázs Odler for the statistical analysis of data, Orion Pharma AB, Espoo, Finland for supporting the study, and Semeco AB, Vejbystrand, Sweden for editorial assistance.

\section{Disclosure}

VM, LT, GG, and MO have no shares in any pharmaceutical companies, and had consultant arrangements with AstraZeneca, Berlin Chemie, Boehringer Ingelheim, Chiesi, GSK, Novartis, Orion, and Takeda. The authors report no other conflicts of interest in this work.

\section{References}

1. Gibson GJ, Loddenkemper R, Sibille Y, Lundbäck B, Fletcher M, editors. European Respiratory Society. European Lung White Book; 2013. Available from: www.erswhitebook.org. Accessed March 12, 2015.

2. Global Initiative for Chronic Obstructive Lung Disease. Global Strategy for Diagnosis, Management and Prevention of COPD; 2014. Available from: www.goldcopd.com. Accessed January 12, 2015.

3. Roberts SD, Farber MD, Knox KS, et al. FEV1/FVC ratio of $70 \%$ misclassifies patients with obstruction at the extremes of age. Chest. 2006; 130(1):200-206.

4. Carolan BJ, Sutherland ER. Clinical phenotypes of chronic obstructive pulmonary disease and asthma: recent advances. J Allergy Clin Immunol. 2013;131(3):627-634.
5. Bujarski S, Parulekar AD, Sharafkhaneh A, Hanania NA. The asthma COPD overlap syndrome (ACOS). Curr Allergy Asthma Rep. 2015; 15(3):509.

6. Decramer M, Selroos O. Asthma and COPD: differences and similarities. With special reference to the usefulness of budesonide/formoterol in a single inhaler (Symbicort) in both diseases. Int J Clin Pract. 2005; 59(4):385-398.

7. Postma DS, Reddel HK, ten Hacken NH, van den Berge M. Asthma and chronic obstructive pulmonary disease: similarities and differences. Clin Chest Med. 2014;35(1):143-156.

8. Tashkin DP, Celli B, Decramer M, et al. Bronchodilator responsiveness in patients with COPD. Eur Respir J. 2008;31(4):742-750.

9. Calverley PM, Albert P, Walker PP. Bronchodilator reversibility in chronic obstructive pulmonary disease: use and limitations. Lancet Respir Med. 2013;1(7):564-573.

10. O’Reilly J, Jones MM, Parnham J, Lovibond K, Rudolf M. Management of stable chronic obstructive pulmonary disease in primary and secondary care: summary of updated NICE guidance. BMJ. 2010;340:c3134.

11. Louie S, Zeki AA, Schivo M, Chan AL, Yoneda KY, Avdalovic M. The asthma-chronic obstructive pulmonary disease overlap syndrome: pharmacotherapeutic considerations. Expert Rev Clin Pharmacol. 2013; 6(2):197-219.

12. Melani AS, Bonavia M, Cilenti V, et al. Inhaler mishandling remains common in real life and is associated with reduced disease control. Respir Med. 2011;105(6):930-938.

13. Lavorini F, Magnan A, Dubus JC, et al. Effect of incorrect use of dry powder inhalers on management of patients with asthma. Respir Med. 2008;102(4):593-604.

14. Chrystyn H, Price D. Not all asthma inhalers are the same: factors to consider when prescribing an inhaler. Prim Care Respir J. 2009;18(4): 243-249.

15. Dolovich MB, Ahrens RC, Hess DR, et al. Device selection and outcomes of aerosol therapy: evidence-based guidelines: American College of Chest Physicians/American College of Asthma, Allergy, and Immunology. Chest. 2005;127(1):335-371.

16. Brocklebank D, Ram F, Wright J, et al. Comparison of the effectiveness of inhaler devices in asthma and chronic obstructive airways disease: a systematic review of the literature. Health Technol Assess. 2001; 5(26):1-149.

17. Schulte M, Osseiran K, Betz R, et al. Handling of and preferences for available dry powder inhaler systems by patients with asthma and COPD. J Aerosol Med Pulm Drug Deliv. 2008;21(4):321-328.

18. Chrystyn H. Closer to an "ideal inhaler" with the Easyhaler®. An innovative dry powder inhaler. Clin Drug Invest. 2006;26(4):175-183.

19. Chrystyn H, Haahtela T. Real-life inhalation therapy-inhaler performance and patient education matter. Eur Respir Dis. 2012;8:11-18.

20. American Thoracic Society. Standardization of spirometry. 1994 update. Am J Respir Crit Care Med. 1995;152(3):1107-1136.

21. Kauppi $P$, Kupiainen H, Lindqvist A, et al. Overlap syndrome of asthma and COPD predicts low quality of life. J Asthma. 2011;48(3):279-285.

22. Andersen H, Lampela P, Nevanlinna A, Saynajakangas O, Keistinen T. High hospital burden in overlap syndrome of asthma and COPD. Clin Respir J. 2013;7:342-346.

23. Suzuki T, Tada Y, Kawata N, et al. Clinical, physiological and radiological features of asthma-chronic obstructive pulmonary disease syndrome. Int J Chron Obstruct Pulmon Dis. 2015;10:947-954.

24. Lavorini F, Fontana GA, Usmani OS. New inhaler devices - the good, the bad and the ugly. Respiration. 2014;88(1):3-15.

25. Perng W-G, Huang H-Y, Chen H-M, Lee Y-C, Perng R-P. Characteristics of airway inflammation and bronchodilator reversibility in COPD. A potential guide to treatment. Chest. 2004;126(2):375-381.

26. Haahtela T, Vidgren M, Nyberg A, Korhonen P, Laurikainen K, Silvasti M. A novel multiple dose powder inhaler. Salbutamol powder and aerosol give equal bronchodilatation with equal doses. Ann Allergy. 1994;72(2): 178-182.

27. Silvasti M, Laurikainen K, Nieminen M, et al. Single dose comparison between a novel multiple dose powder inhaler and a conventional metered dose inhaler in asthmatic patients. Acta Ther Res. 1993;19:125-135. 
28. Nieminen M, Vidgren M, Laurikainen K, et al. Easyhaler ${ }^{\circledR}$, a novel multiple dose powder inhaler: clinically equivalent to salbutamol metered dose inhaler and easier to use. Respiration. 1994;61(1):37-41.

29. Tammivaara R, Aalto E, Lehtonen K, et al. Comparison of a novel salbutamol multidose powder inhaler with a salbutamol metered dose inhaler in patients with asthma. Curr Ther Res. 1997;58(10):734-744.

30. Guyatt GH, Townsend M, Nogradi S, Pugsley SO, Keller JL, Newhouse MT. Acute response to bronchodilator. An imperfect guide for bronchodilator therapy in chronic airflow limitation. Ann Intern Med. 1988;148(9):1949-1952.

31. Brand PL, Quanjer PH, Postma DS, et al. Interpretation of bronchodilator response in patients with obstructive airways disease. Thorax. 1992;47(6):429-436.

32. Tan WC, Vollmer WM, Lamprecht B, et al. Worldwide pattern of bronchodilator responsiveness: results from the Burden of Obstructive Lung Disease study. Thorax. 2012;67(8):718-726.

33. Pellegrino R, Viegi G, Brusasco V, et al. Interpretative strategies for lung function tests. Eur Respir J. 2005;26(5):948-968.

34. Albert P, Agusti A, Edwards L, et al. Bronchodilator responsiveness as a phenotypic characteristic of established chronic obstructive pulmonary disease. Thorax. 2012;67(8):701-708.

35. Miller MR, Hankinson J, Brusasco V, et al. Standardisation of spirometry. Eur Respir J. 2005;26(2):319-338.

36. IPPB Trial Group. Intermittent positive pressure breathing therapy of chronic obstructive pulmonary disease. A clinical trial. Ann Intern Med. 1985;99(5):612-620.

37. Celli BR, MacNee W. Standards for the diagnosis and treatment of patients with COPD: a summary of the ATS/ERS position paper. Eur Respir J. 2004;23(6):932-946.

38. Janssens JP, Pache JC, Nicod LP. Physiological changes in respiratory function associated with ageing. Eur Respir J. 1999;13:197-205.

39. Palander A, Mattila T, Karhu M, Muttonen E. In vitro comparison of three salbutamol-containing multidose dry powder inhalers. Buventol Easyhaler ${ }^{\circledR}$, Inspiryl Turbuhaler®, and Ventoline Diskus. Clin Drug Invest. 2000;20(1):25-33.
40. Vidgren M, Silvasti M, Korhonen P, Kinkelin A, Frischer B, Stern K Clinical equivalence of a novel multiple dose powder inhaler versus a conventional metered dose inhaler on bronchodilating effects of salbutamol. Arzneim.-Forsch/Drug Res. 1995;45:44-47.

41. Newman SP, Pitcairn GR, Adkin DA, Vidgren MT, Silvasti M. Comparison of beclomethasone dipropionate delivery by Easyhaler ${ }^{\circledR}$ dry powder inhaler and pMDI plus large volume spacer. J Aerosol Med. 2001;14(2):217-225.

42. Gálffy G, Mezei G, Németh G, et al. Inhaler competence and patient satisfaction with Easyhaler: results of two real-life multicentre studies in asthma and COPD. Drugs RD. 2013;13(3):215-222.

43. Giner J, Torrejón M, Ramos A, et al. Patient preference in the choice of dry powder inhalers. Arch Bronconeumol. 2004;40(3):106-109.

44. Broeders MEAC, Vincken W, Corbetta L; On behalf of the ADMIT Working Group. The ADMIT series - Issues in Inhalation Therapy. 7. Ways to improve pharmacological management of COPD: the importance of inhaler choice and inhalation technique. Prim Care Respir J. 2011; 20(3):338-343.

45. Vincken W, Dekhuijzen R, Barnes P; On behalf of the ADMIT group. The ADMIT series - Issues in Inhalation Therapy. 4. How to choose inhaler devices for the treatment of COPD. Prim Care Respir J. 2010; 19(3):10-20.

46. Lavorini F, Fontana GA. Inhaler technique and patient's preference for dry powder inhaler devices. Expert Opin Drug Deliv. 2014; 11(1):1-3

47. Müller V, Gálffy G, Eszes N, et al. Asthma control in patients receiving inhaled corticosteroid and long-acting beta2-agonist fixed combinations A real-life study comparing dry powder inhalers and a pressurized dose metered dose inhaler extrafine formulation. BMC Pulm Med. 2011;11(1):40.
International Journal of COPD

\section{Publish your work in this journal}

The International Journal of COPD is an international, peer-reviewed journal of therapeutics and pharmacology focusing on concise rapid reporting of clinical studies and reviews in COPD. Special focus is given to the pathophysiological processes underlying the disease, intervention programs, patient focused education, and self management protocols.

\section{Dovepress}

This journal is indexed on PubMed Central, MedLine and CAS. The manuscript management system is completely online and includes a very quick and fair peer-review system, which is all easy to use. Visit http://www.dovepress.com/testimonials.php to read real quotes from published authors. 